\title{
Court interpreting: algumas interfaces com a interpretação de conferências
}

Reynaldo J. Pagura*

\section{Considerações iniciais}

Em primeiro lugar, faz-se necessário esclarecer o porquê da escolha da expressão "court interpreting", em inglês, no título, em vez de "interpretação judicial" ou "interpretação em juízo", em português. A questão aqui vai muito além de uma possível equivalência dos dois termos. Este artigo pretende focalizar a interpretação que ocorre no sistema judiciário dos Estados Unidos que, na experiência e opinião do autor, é bastante diferente do que acontece quando da atuação do tradutor juramentado em sua função de intérprete judicial no Brasil.

A atuação do intérprete em juízo no Brasil costuma ocorrer com muito menos frequência do que nos Estados Unidos e acontece quase sempre em um tipo de processo: casos relacionados a estrangeiros presos por envolvimento em tráfico de drogas. Essa é a experiência do autor e de diversos colegas que exercem a função como tradutores juramentados na cidade de São Paulo e que são, ocasionalmente, convocados a atuar em juízo. Nos Estados Unidos, em função do imenso número de estrangeiros residentes no país e da

\footnotetext{
* Reynaldo J. Pagura é doutor em Letras pela USP e mestre em Aquisição de Linguagem pela Brigham Young University, nos EUA. É professor (licenciado) do Departamento de Inglês da PUC-SP, tradutor público e intérprete comercial do Estado de São Paulo e intérprete judicial (court interpreter) do Sistema Judiciário do Estado de Utah, nos Estados Unidos.
} 
judicialização muito maior da própria sociedade, é bastante comum recorrer-se ao judiciário para a resolução de uma ampla gama de conflitos, muitos deles incluindo participantes denominados LEPs (Limited English Proficiency), o que exige a intervenção de intérpretes.

Outra diferença radical entre o Brasil e os Estados Unidos na área em discussão é que no Brasil o "credenciamento" se faz a partir da função de tradutor público (ou juramentado) que, ocasionalmente, atua como intérprete - sem qualquer formação para isso e sem qualquer experiência na área de interpretação. Não existe nos Estados Unidos a figura equivalente à do tradutor público (ou juramentado) do Brasil, embora exista um processo de "certificação" da American Translators Association, que nada tem a ver com as características do processo de seleção e nomeação do tradutor público brasileiro. Por outro lado, em praticamente todos os estados dos Estados Unidos e também no judiciário federal faz-se, isso sim, o credenciamento de intérpretes para atuar em juízo. Tal processo será explicitado, ainda que de forma sucinta, mais à frente.

\section{Breve resumo do sistema judiciário dos Estados Unidos e suas implicações quanto à atuação de intérpretes}

Pode-se afirmar, em termos simplificados, que os Estados Unidos possuem 51 sistemas judiciários: um sistema federal e um sistema estadual distinto e independente em cada um dos 50 estados, com diferenças de legislação e funcionamento. Os nomes das diferentes instâncias costumam, também, variar de um estado para outro. Além disso, os estados têm, ainda, instâncias dos municípios e dos condados, uma divisão política dos estados, acima do nível municipal. Usualmente, essas instâncias de munícipio e condado recebem o nome de Justice Courts, enquanto as instâncias estaduais costumam ser chamadas de District Courts ou Trial Courts em grande parte dos estados (mas não em todos). A imensa maioria dos processos - mais de $98 \%$ - acontece na esfera estadual (A.B.A., 2008). São relativamente poucas as situações em que os processos ocorrem na esfera federal. Em grande parte dos casos, a instância 
máxima de recurso ainda é estadual, uma vez que quase todos os estados têm a sua própria Supreme Court estadual (cujo nome também pode variar de um estado para outro), diferente do que ocorre no sistema judiciário brasileiro, em que a terceira instância é federal. São pouquíssimos os casos que chegam à famosa Supreme Court of the United States, localizada na capital federal.

Ainda de relevância para a questão da atuação de intérpretes, salientase que o processo jurídico da common law, que predomina nos países de língua inglesa, tende mais à oralidade, com a cross-examination entre as diversas partes do processo (réu, testemunhas, advogados e juiz) e, ainda, os discursos de abertura e de conclusão por parte dos advogados para convencimento do júri. É também útil esclarecer que os júris fazem parte da maioria dos julgamentos da área cível e penal, uma diferença fundamental do Direito Romano que constitui o ordenamento jurídico brasileiro. A tradição do Direito Romano, muito mais codificado, tem como base as peças processuais escritas e a não utilização de júris, excetuando-se os processos de crimes dolosos contra a vida, o que reduz em muito a oralidade durante os procedimentos jurídicos. Essa oralidade presente nos juízos dos Estados Unidos exige, é claro, a presença de intérpretes quando as partes, as testemunhas ou, porventura, algum perito não tenha pleno domínio da língua inglesa. Não só é um direito garantido a ambas as partes, mas o intérprete tem função importantíssima para os autos, uma vez que é a tradução provida pelo intérprete que fará parte dos registros, e não o depoimento ou a opinião de um perito, se ocorrer em língua estrangeira.

Ressalta-se, ainda, que a atuação de intérpretes ocorre sempre em primeira instância, quer estadual ou federal, e não nos tribunais de recurso de segunda instância (appelate courts) ou, ainda, de terceira instância (supreme courts ou courts of last resort). Nos recursos, tal como no sistema brasileiro, não há a presença de testemunhas, não há depoimentos das partes e não há jurados, uma vez que não se admitem novas provas ou novos fatos. A função dos recursos, quer sejam estaduais ou federais, é avaliar o julgamento da primeira instância e, em termos simplificados, decidir quanto à sua correção, nos mesmos moldes do que ocorre no judiciário brasileiro. 


\section{O credenciamento de intérpretes}

Não está dentro do escopo do presente artigo fazer uma descrição detalhada e exaustiva do processo de credenciamento de intérpretes judiciais nos Estados Unidos, uma vez que tal descrição seria, entre outras coisas, longuíssima. Ao contrário do Brasil, onde os concursos para tradutores públicos e intérpretes comerciais são normatizados pelo Decreto Federal 13.609, de 21 de outubro de 1943 - ainda que realizados pelas Juntas Comerciais dos estados -, o credenciamento de intérpretes judiciais nos Estados Unidos é de responsabilidade do sistema judiciário de cada um dos estados ou, ainda, do judiciário federal. Os títulos dados a diferentes categorias de intérpretes dentro de cada sistema, as etapas do processo de credenciamento e, ainda, as diferentes línguas oferecidas variam de um estado para outro.

O sistema federal credencia intérpretes em apenas três línguas: espanhol, navajo e crioulo haitiano, a partir de legislação promulgada em 1978 (Court Interpreters Act - Public Law 95-539), emendada em 1988 (Court Interpreters Amendments Act - Public Law 100-702) e ratificada pela Executive Order (decreto presidencial) nํ13166, de 2000 (Ver, entre outros, Berk-Seligson, 1990, Edwards, 1995 e de Jongh, 2012).

Tomando como modelo a legislação federal, os diversos estados começaram a legislar sobre o assunto, sistematizando o credenciamento e o direito à utilização de intérpretes em suas instâncias jurídicas. Em seu Apêndice 1, Berk-Selingson (1990, p. 219-222) apresenta a legislação dos estados, em ordem alfabética, regulamentando o direito a intérpretes em cada um deles. Os sistemas estaduais oferecem credenciamento em diversos idiomas, variando imensamente de um estado para outro conforme as tendências imigratórias e outras características locais. Como curiosidade, é interessante mencionar que são diversos os estados que já oferecem credenciamento de intérpretes judiciais de língua portuguesa, o que atualmente tem muito mais a ver com a residência de brasileiros nesses estados 
do que com a tradicional e antiga imigração portuguesa em Massachusetts e em algumas regiões da Califórnia.

Em linhas gerais, o processo de credenciamento de intérpretes nos diversos estados do país é semelhante. Via de regra, há provas escritas e provas orais. As provas escritas normalmente incluem uma prova do código de ética dos intérpretes do estado em questão e uma prova escrita, comum a muitos estados, produzida pelo National Center for State Courts, Language Access Services Section. Essa prova, fornecida em diferentes versões, é comumente adquirida pela administração dos sistemas judiciários estaduais e aplicada aos candidatos, como parte do processo. Trata-se de uma prova de "inglês jurídico", comum a candidatos de todos os idiomas, com 135 questões de múltipla escolha. Exige-se o mínimo de 80\% de acertos, ou seja, 108 questões. A prova contém, ainda, questões de conhecimento básico de processo cível e processo penal, a fim de verificar se os intérpretes entendem os procedimentos jurídicos básicos em que estarão envolvidos, e questões de natureza ética em geral, ou seja, não específicas do código de um determinado estado.

É, ainda, comum que os estados exijam, obviamente, proficiência na língua estrangeira à qual o candidato pretende se credenciar. Essa proficiência é comprovada, usualmente, por meio da prova chamada Oral Proficiency Interview, conhecida pela sigla OPI, que é oferecida pela ACTFL - American Council on the Teaching of Foreign Languages - em diversos idiomas. Não deixa de ser curioso mencionar que essa prova é exigida mesmo dos candidatos que falam o idioma a que se candidatam como língua materna, o que é um certo contrassenso, em termos de medidas de avaliação, já que a prova tem como objetivo medir o grau de proficiência que o estrangeiro (basicamente o candidato americano) possui em uma determinada língua que não o inglês. Observe-se que o órgão responsável pela prova é o Conselho Americano para o Ensino de Línguas Estrangeiras. Assim, o brasileiro que tenha de se submeter ao OPI em português não está, é claro, fazendo uma prova em língua estrangeira, mas sim em sua língua materna. Em termos de medida de avaliação, a prova não teria validade, uma vez que não está medindo o que 
propõe, ou seja, a proficiência em uma língua estrangeira. No entanto, o sistema judiciário dos estados não conta com especialistas em medidas de avaliação para chegar a tal nível de sofisticação em termos de linguística aplicada. É possível entender o raciocínio das administrações dos sistemas judiciários estaduais: não há como essas administrações avaliarem o nível de sofisticação com que um candidato utiliza uma língua, ainda que seja a sua língua materna. E, ainda, ficaria bastante difícil, inclusive em termos jurídicos, avaliar por critérios diferentes candidatos de língua inglesa materna que falam uma língua estrangeira e candidatos de outras línguas maternas. Observe-se que a prova escrita mencionada no parágrafo anterior é a mesma (em inglês) para candidatos que falem inglês ou qualquer outro idioma como língua materna.

Grande parte dos estados exige, ainda, diversas horas de observação de audiências e julgamentos em que haja a atuação de intérpretes e a participação em workshops de orientação e de treinamento. Depois de aprovação e cumprimento dessas etapas, os intérpretes podem começar a atuar, ainda que não sejam considerados "certificados", como se denominam os intérpretes de nível mais alto de cada sistema estadual.

Para serem considerados "certificados", os intérpretes da maior parte dos estados têm de se submeter a provas de interpretação consecutiva e de interpretação simultânea, nas duas direções - do inglês para a língua estrangeira e da língua estrangeira para o inglês. Essas provas também são produzidas pelo consórcio denominado National Center for State Courts e estão disponíveis em diversos idiomas, que estão sendo frequentemente acrescidos de novos, conforme necessidade e, também, disponibilidade de profissionais capacitados para a avaliação. As provas são fornecidas em CDs e são adquiridas pelos estados. São administradas localmente e devolvidas para o National Center for State Courts para avaliação. Por essa razão, é comum os estados aceitarem a transferência de intérpretes certificados de um estado para outro, já que quase todos utilizam sistema semelhante e as provas elaboradas pelo National Center for State Courts. 


\section{A atuação dos intérpretes no dia a dia}

A grande maioria dos intérpretes atuantes nos diversos níveis e idiomas dos sistemas judiciários estaduais, de condados, municipais e, também, no sistema federal são profissionais freelance. Há, em alguns estados, um número mínimo de intérpretes - sempre de espanhol - que são funcionários permanentes do judiciário, uma vez que o espanhol é a língua de maior demanda em todos os níveis do judiciário dos Estados Unidos. É também de espanhol a maior parte dos intérpretes credenciados em todas as categorias em todos os estados. Esses intérpretes freelance de espanhol atendem à necessidade que não consegue ser suprida pelos intérpretes-funcionários. Para todos os demais idiomas, os intérpretes atuam sempre de maneira independente, embora os estados determinem a sua própria escala de pagamentos de honorários.

Há argumentação entre os intérpretes e muitas vezes surge a discussão no âmbito da NAJIT (National Association of Judiciary Interpreters and Translators) quanto a essa questão, uma vez que, tecnicamente, o profissional freelancer é aquele que pode determinar seus honorários. Uma vez que os estados determinam os honorários, não podem argumentar que os intérpretes são totalmente independentes. Apesar de antiga, a discussão nunca conseguiu modificar o sistema. Os intérpretes continuam, sempre, a ser a parte mais fraca do sistema e já houve, inclusive, movimentos de intérpretes em alguns estados. Nunca, porém, se conseguiu alterar o sistema, ainda que se consiga, ocasionalmente, algum aumento dos honorários, que continuam, sempre, determinados pela parte mais forte, a saber, os estados e o governo federal.

Uma vez que o sistema federal só credencia intérpretes nos três idiomas mencionados acima, quando se faz necessária a atuação de intérpretes de outros idiomas, é comum que as instâncias federais recorram aos intérpretes estaduais residentes no estado em que os diversos juízos federais atuam ou, ainda, a intérpretes estaduais de estados próximos. Tal procedimento é bastante comum, por exemplo, nos juízos de imigração, existentes em quase todos os estados. Por sua própria natureza, envolvem a presença de 
estrangeiros que não dominam o inglês e são, sempre, federais, uma vez que a União não delega questões de imigração aos estados.

Os sistemas municipais e dos condados também não costumam ter sistema de credenciamento de intérpretes. Essas justice courts lidam com casos mais simples, muitas vezes relacionados a questões de trânsito - avanços de sinais, direção sem documentos, direção sob o efeito de bebidas alcóolicas ou drogas e também uma grande variedade de questões relacionadas ao que chamamos de "pequenas causas", cuja limitação financeira é definida pelos diferentes juízos. Observe-se que em todos os casos, o acusado deve comparecer perante um juiz para se explicar, ocasionando a necessidade da presença do intérprete se uma das partes não conseguir se expressar em inglês. Pode haver até mesmo júri, principalmente nos casos de embriaguez ou uso de drogas ao volante, uma vez que são passíveis de pena de prisão, além de multa. É comum que essas instâncias recorram aos intérpretes credenciados pelo sistema estadual em que se localizam.

Em resumo, os sistemas judiciários estaduais são uma espécie de "celeiro" de intérpretes em uma determinada região. É comum todas as instâncias recorrerem aos websites dos sistemas judiciários estaduais e chamarem intérpretes ali relacionados. É, ainda, comum recorrer-se a essas listagens quando alguém ou alguma organização na comunidade necessita intérpretes para situações não jurídicas. É também comum os escritórios de advocacia recorrerem a essa listagem estadual quando precisam de tradução de documentos. Em outras palavras, fazer parte da lista de intérpretes credenciados de um sistema judiciário estadual funciona como uma vitrine de serviços de interpretação e até mesmo de tradução, já que a maior parte do público não diferencia entre intérprete e tradutor. O próprio sistema judiciário costuma recorrer a seus intérpretes credenciados quando precisa da tradução escrita de algum documento.

Quanto às modalidades de interpretação utilizadas no dia a dia da atuação dos court interpreters nos juízos dos Estados Unidos, é comum utilizarse, em grande parte do tempo, a interpretação simultânea, quer sussurrada 
quer com o uso de equipamento portátil, comumente chamado de "miniequipo". Raras são as instâncias que possuem cabines de interpretação, embora essas existam em alguns lugares. Essa interpretação simultânea ocorre do inglês para a língua estrangeira, para atender à parte (ou partes) que não domine o inglês e não consiga acompanhar o que está acontecendo no processo. Esse é considerado um direito garantido a todos os envolvidos no sistema judiciário dos Estados Unidos, tanto por legislação federal quanto por legislação individual dos estados, conforme mencionado anteriormente. Quando a parte não-falante de inglês tem de se expressar em um depoimento ou prestar qualquer esclarecimento solicitado pelo juiz, promotor ou advogados, o intérprete atua em consecutiva da língua estrangeira para o inglês, a fim de que todos os participantes entendam esse depoimento ou aparte. É essa interpretação para o inglês que é registrada nos autos, como já se mencionou. Atua, ainda, em simultânea sussurrada traduzindo as perguntas ou comentários para a parte que não domina o inglês. Há alguns casos em que o juiz determina que possíveis perguntas do inglês para a língua estrangeira sejam traduzidas em consecutiva, de modo audível, para a parte que está sendo inquirida. Isso acontece, geralmente, nos casos em que advogados das partes falem o idioma do estrangeiro envolvido e queiram acompanhar a interpretação, ou seja, queiram confirmar se a tradução do intérprete reflete exatamente a pergunta feita. É um procedimento mais comum quando o idioma envolvido é o espanhol, atualmente falado por grande número de pessoas nos Estados Unidos.

É possível ainda a atuação do intérprete na realização de tradução oral de um texto escrito (sight translation), quer seja um documento que se apresente durante o processo, quer seja algum formulário que precise ser preenchido pela parte com limitações no uso do inglês. O intérprete é sempre instruído a não preencher formulários ou orientar o seu preenchimento. Deve, apenas, traduzir o que está escrito no formulário. Na prática, muitas vezes as coisas se misturam, e a "tradução somente", como os juízos instruem, não possibilita o preenchimento adequado e o intérprete acaba por atuar como 
uma espécie de mediador cultural, faceta do intérprete que se discutirá mais à frente.

\section{Interfaces entre a "court interpreting" e a interpretação de conferências}

Por meio da experiência e atuação nas duas modalidades, é possível chegar-se à conclusão de que existem mais semelhanças do que diferenças entre a atuação do intérprete de conferências e do court interpreter, pelo menos no que tange a seu trabalho no sistema judiciário dos Estados Unidos.

Não se pode deixar de lembrar que a própria história da interpretação de conferências, ou mais especificamente o uso da interpretação simultânea em larga escala entre vários idiomas, está ligada à interpretação em um evento de natureza eminentemente jurídica, a saber, os famosos julgamentos dos líderes da derrotada Alemanha Nazista, realizado em Nuremberg ao final da Segunda Guerra Mundial em 1945-1946. Vários dos intérpretes que atuaram em Nuremberg vieram a fazer carreira na ONU ou como intérpretes de conferência freelance. Em termos simples, passaram de uma atuação em juízo para uma atuação em conferências internacionais.

Um dos elementos sempre presentes em relação ao trabalho dos intérpretes é a questão da neutralidade e/ou da invisibilidade do intérprete a premissa de que o intérprete é totalmente neutro e não se envolve, de modo algum, no conteúdo do que está traduzindo. A questão está presente quando se discute a interpretação de conferências e está sempre presente também quando se discute o papel do intérprete em juízo. Em parte, a ideia parte da presunção, normalmente por parte de pessoas leigas à área, de que é possível traduzir "apenas as palavras", traduzir literalmente de uma língua para outra, com o intérprete fazendo o papel de pouco mais do que um robô que substitui palavras entre idiomas, num suposto ato comunicativo. Todos os envolvidos na profissão sabem que tal "neutralidade" total e absoluta não é completamente possível. As próprias associações de classe prestam uma espécie de desserviço à profissão quando prescrevem, em códigos de conduta 
para o intérprete (talvez para tranquilizar os usuários da interpretação), a sua função como sendo a de uma parte neutra ou invisível

\begin{abstract}
cujo papel é transmitir significado com precisão em outra língua. O que se presume dessas declarações dos códigos de ética de diversas organizações [...] é que qualquer enunciado linguístico terá apenas um significado específico, que não está sujeito a uma co-construção por todos os envolvidos na interação (incluindo o intérprete) mas sim que esse enunciado tem sentido independente das partes (Angelelli, 2004, p. 20). ${ }^{1}$
\end{abstract}

Tanto o usuário da interpretação de conferências quanto os diversos participantes do sistema judiciário parecem ter uma verdadeira obsessão com o papel do intérprete, uma espécie de medo contínuo de que o intérprete não esteja sendo "fiel" - "fidelidade" sendo, para os leigos à profissão, a tradução de "todas as palavras do original". Cada vez mais, a impressão que o autor do presente artigo tem é que os intérpretes não discutem a questão com seus usuários, mas realizam seu trabalho sem se ater a esse aspecto de uma pseudofidelidade impossível de se atingir. Como reitera Hale (2007),

os intérpretes competentes sempre consideram o contexto cultural em suas traduções. Não existe algo como "ato tradutório básico" como coloca Barsky (2000) quando compara o que os tribunais esperam que os intérpretes façam e o que ele gostaria que fizessem. Se a tradução não levar em consideração as implicações culturais da mensagem, não pode ser considerada como uma "tradução profissional" (p. 88).

Um pouco mais à frente em seu texto, Hale continua, chamando a atenção para o fato de que existe uma concepção errônea de que a tradução literal significa fidelidade e que "estão sendo feitos esforços para acabar com esse mito" (op. cit., p. 93). Um pouco mais à frente, ainda, a autora menciona uma série de estudiosos que questionam os códigos de ética das organizações, que ajudam a perpetuar o mito da "precisão e imparcialidade" do trabalho executado pelos intérpretes. “O argumento é que os códigos prescrevem um

\footnotetext{
${ }^{1}$ Todas as traduções das citações são do autor do presente artigo.
} 
ideal impossível, que não reflete o desempenho dos praticantes da profissão na vida real" (op. cit., p. 105). Está aí um elemento em comum entre a interpretação de conferências e a interpretação em juízo ou court interpreting, que vem sendo cada vez mais estudado por diversos pesquisadores dos Estudos da Interpretação e para o qual as associações de classe de intérpretes de conferência e de intérpretes judiciais precisam estar atentas e se posicionar de maneira mais coerente com a realidade.

Outra interface que se pode mencionar entre as duas modalidades de interpretação em discussão é o caráter monológico das falas interpretadas pelos intérpretes de conferência e por seus colegas atuantes em situações judiciais. Esse caráter monológico contrasta com o caráter dialógico de outras modalidades de interpretação como a interpretação da área médica e de outras situações comunitárias, em que o intérprete traduz uma espécie de interlocução dialógica entre médico e paciente ou entre usuário e prestador de um determinado serviço. Segundo Angelelli (2004), “em juízo, por exemplo, a interpretação é altamente formalizada. Só é possível dirigir-se aos interlocutores de uma determinada maneira, e os turnos da fala são regulados. Tais características não aparecem na interpretação comunitária" (p. 87). Poderíamos acrescentar, sem dúvida alguma, que na maior parte dos casos a interpretação de conferências ocorre em situações muito semelhantes às mencionadas por Angelelli ao descrever a interpretação em juízo. Dificilmente uma conferência internacional em que haja intérpretes atuando terá o nível de informalidade de uma interação interpretada numa situação de interpretação comunitária, em que um estrangeiro utiliza um intérprete para preencher um formulário numa repartição pública ou uma mãe conversa com a professora de seu filho, sendo que cada uma das partes fala um idioma diferente como língua materna e, por isso, faz-se necessária a intervenção de um intérprete comunitário. Em resumo, a interpretação de conferências e a interpretação judicial acontecem em ambientes mais formalizados do que a interpretação comunitária, por exemplo. 
Outra interface importante entre as modalidades de interpretação em discussão refere-se ao papel do intérprete como mediador cultural. Esse papel é aceito mais facilmente para o intérprete de conferências e, normalmente, está presente em sua formação, quando se estimula o intérprete a ser um mediador cultural. Essa posição é clássica na formação de intérpretes de conferências:

Constate-se em todas as interpretações as modificações devidas às relações entre o explícito-implícito na formulação original. Os ouvintes do intérprete não são os mesmos que escutam diretamente o orador; o intérprete tem consciência de sua presença e os leva em consideração; [...] ele adapta o discurso a eles e, para fazê-lo, explicita ou modifica aquilo que o desconhecimento cultural do outro [o ouvinte da interpretação] faria com que ficasse à margem [da mensagem] (Seleskovitch e Lederer, 2002, p. 265).

A questão é bem mais controversa no exercício da interpretação em juízo. Como já se mencionou acima, existe certa ilusão por parte dos diferentes usuários da interpretação de que é possível que haja uma tradução "apenas das palavras" e que esta seria a tradução "mais fiel", conceito este muito comum aos leigos à área dos Estudos da Tradução e da Interpretação. O "grande público" sempre tem o conceito de que a tradução "mais fiel" é aquela que converte apenas as palavras de um idioma para outro. Assim, o intérprete seria apenas um dicionário ambulante, dotado de fala, capaz de rapidamente converter as palavras de um idioma a outro. Embora possa parecer um exagero, essa imagem não é muito diferente do que aquela que o leigo faz do intérprete. Como nos diz uma das mais importantes estudiosas da interpretação judicial (Mikkelson, 2000), “o que constitui uma interpretação competente na esfera jurídica não é uma questão simples", e mais à frente em seu texto trata especificamente da questão do intérprete como mediador cultural, dizendo que

há também diferentes opiniões a respeito de até onde o intérprete deve ir para cobrir lacunas culturais e sociais no ambiente judicial. Em um extremo, há aqueles que advogam que o intérprete se atenha estritamente aos elementos linguísticos da mensagem. [...] No outro extremo, há aqueles que argumentam 


\begin{abstract}
que as lacunas culturais são às vezes tão grandes que o foco somente nos elementos linguísticos não consegue transmitir informações significativas e (a interpretação) acaba não tendo propósito. [...] A maioria dos intérpretes assume uma posição intermediária entre esses dois extremos, e cada caso deve ser julgado de acordo com as circunstâncias (p. 3-4).
\end{abstract}

A tendência do autor é concordar inteiramente com Mikkelson quando ela diz que "a maioria dos intérpretes assume uma posição intermediária". É óbvio que não podemos nos ater a uma mera conversão de palavras - isso é ponto pacífico para todos os profissionais da área - como, às vezes, nos instruem juízes ou advogados não conhecedores de questões linguísticas. É claro também que os intérpretes, quer em situações de conferências ou de processos judiciais, podem fazer grandes acréscimos e acrescentar diversas explicações a fim de explicitar questões culturais. O bom senso deve sempre prevalecer e as questões culturais devem, sempre que possível, ser esclarecidas pela cuidadosa escolha de palavras e expressões pelo intérprete, a fim de que se esclareçam sutilmente no corpo do próprio enunciado da interpretação.

Por fim, cabe aqui mencionar brevemente alguns aspectos profissionais em que o intérprete de conferências exerce sua profissão em condições um pouco mais favoráveis do que seu colega que atua em juízo. Uma delas é a preparação. Usualmente, o intérprete atua em juízo com muito pouca informação prévia sobre a situação em que vai atuar. Muitas vezes a informação prévia que se recebe é extremamente sucinta, como por exemplo, "warrant bench trial", "pre-trial evaluation" ou ainda "grandparents visitation rights", citando três exemplos reais do autor recebidos na semana anterior à redação do presente artigo. Quando se trata de atuação em juvenile court (uma espécie de juizado de menores), mais comum do que se pode imaginar, as informações são ainda mais reduzidas, justamente por se tratar de processos em que estão envolvidos menores de idade. Muitas vezes é possível conversar com as partes envolvidas ou com os advogados antes da sessão, mas nem sempre isso acontece. Há ocasiões em que essa falta de informações é ainda mais grave, pois a atuação é remota - o intérprete usualmente está na capital 
do estado e o caso ocorre numa outra cidade do estado, a mais de 400 quilômetros de distância. Utiliza-se equipamento remoto, com áudio e vídeo, mas existem muitas vezes problemas de câmera, em que a câmera não focaliza exatamente o que ou quem o intérprete precisa ver ou uma das partes não fala próximo ao microfone. Normalmente, o intérprete de conferências se recusaria a trabalhar sem informações prévias mais precisas e em condições remotas tão difíceis em termos técnicos.

O problema de som e microfone não ocorre somente na interpretação remota. Nas salas em que o intérprete está presente, é bastante comum que os advogados, promotores ou assistentes sociais falem totalmente fora do microfone, dirigindo-se ao juiz. Em muitos casos, o intérprete está localizado atrás dessas pessoas, sentado ao lado da parte que não entende inglês, e não pode acompanhar suas expressões faciais e gestos. Com frequência, é preciso interromper e solicitar ao juiz que determine que a pessoa em questão fale ao microfone. Os juízes usualmente são bastante solícitos às necessidades dos intérpretes e, imediatamente, mandam que os advogados e outros falem ao microfone para que o intérprete possa ouvir. No entanto, após poucos minutos é comum que a pessoa se afaste novamente do microfone. O intérprete tenta fazer o melhor possível para escutar, mas é difícil acompanhar todos os detalhes da fala. Pode-se, mais uma vez, solicitar ao juiz, mas a maior parte dos intérpretes evita insistir nessas solicitações o tempo todo, pois acaba passando a imagem de que é ele quem está com dificuldades para executar o seu trabalho. É difícil imaginar tal situação na interpretação de conferências, uma vez que o intérprete deixaria de escutar na cabine e pararia a interpretação, interrompendo o evento para grande número de participantes. Na situação em juízo, normalmente só quem perde a interpretação é uma ou duas pessoas, justamente aqueles que não entendem inglês.

Outra situação de desvantagem dos intérpretes judiciais é a falta do conforto e isolamento proporcionado pelas cabines. Com raríssimas exceções, trabalha-se com o som ambiente e equipamento portátil ou interpretação sussurrada. Nos depoimentos, como já mencionado, atua-se em consecutiva. 
Embora o equipamento portátil possibilite que o intérprete se locomova pela sala a fim de poder estar de frente para as pessoas que estão fazendo uso da palavra - os juízes estão, via de regra, cada vez mais acostumados com o trabalho dos intérpretes e não estranham seu deslocamento pela sala para ouvir melhor - ainda assim trabalha-se com o som ambiente, o que é nitidamente inferior ao som recebido por fones de ouvido no isolamento sonoro da cabine. $\mathrm{O}$ uso de cabines parece só ocorrer em julgamentos com repercussão na mídia e/ou de projeção internacional, e raramente ocorre no dia a dia do trabalho regular do court interpreter.

\section{Comentários finais}

O presente artigo pretendeu dar uma visão ao leitor brasileiro, interessado em questões relacionadas aos Estudos da Interpretação, do que ocorre no dia a dia do trabalho do court interpreter nos Estados Unidos. Pretendeu apresentar uma visão não idealizada do exercício da profissão e que difere talvez um pouco de outras publicações da área, que via de regra, são escritas do ponto de vista do intérprete e/ou pesquisador ligado ao espanhol, principal idioma de trabalho dos court interpreters que atuam nos Estados Unidos.

As comparações e contrastes com a interpretação de conferências pretendem estender a área de interesse do artigo e mostrar que, do mesmo modo que um pianista pode tocar clássico e popular, o intérprete também pode, sem grandes dificuldades de adaptação, atuar em conferências e em juízo. De fato, isso é razoavelmente comum nos Estados Unidos, país em que, na maior parte dos estados, a demanda pela interpretação de conferências é razoavelmente pequena, mesmo para os intérpretes que tenham o espanhol como principal língua de trabalho. Para outras línguas, como o português, a demanda é mínima. Por outro lado, a necessidade de interpretação no judiciário é contínua para diversos idiomas além do espanhol, incluindo-se aí o português. Assim, há muito mais trabalho in court do que em conferências. Isso explica, até certo ponto, por que há, nos Estados Unidos, diversos programas para a formação de court interpreters e, basicamente, apenas dois (no 
Middlebury Institute of International Studies, em Monterey, Califórnia, e na Universidade de Maryland, nos arredores de Washington, D.C.) dedicados à formação de intérpretes de conferências, ainda assim em departamentos que também oferecem formação em tradução. Um dos programas de formação de intérpretes mais antigos do mundo, o da Universidade de Georgetown, também em Washington, D.C., foi encerrado há vários anos. Há, também, muito mais pesquisa acadêmica voltada para a interpretação em juízo, médica e comunitária do que na área voltada para a interpretação de conferências, como acontece nas universidades europeias. Aplica-se, assim, a inexorável regra da oferta e procura: a demanda por court interpreting, gerada pela imigração para os Estados Unidos, leva a programas de formação, pesquisa, associações de classe e legislação que proporcionam o acesso à justiça para os denominados "linguistically disadvantaged" (Berg-Seligson, 1990, p. 34).

\section{Referências}

A.B.A. (American Bar Association). Law \& The Courts, volume 1: The Role of the Courts. Chicago: ABA - Division for Public Education, 2008.

ANGELELLI, Claudia V. Revisiting the Interpreter's Role. Amsterdam/Philadelphia: John Benjamins, 2004.

BERK-SELIGSON, Susan. The Bilingual Courtroom: Court Interpreters in the Judicial Process. Chicago and London: The University of Chicago Press, 1990.

DE JONGH, Elena M. From the Classroom to the Courtroom: a guide to interpreting in the U.S. justice system. American Translators Association Scholarly Monograph Series XVII. Amsterdam/Philadelphia: John Benjamins, 2012.

EDWARDS, Alicia B. The Practice of Court Interpreting. Amsterdam/Philadelphia: John Benjamins, 1995.

HALE, Sandra Beatriz. Community Interpreting. Houndmills, Hampshire (UK)/New York: Palgrave Macmillan, 2007.

MIKKELSON, Holly. Introduction to Court Interpreting. Manchester, UK \& Northampton, MA: St. Jerome Publishing, 2000. 
SELESKOVITCH, Danica e LEDERER, Marianne. Pédagogie raisonnée de l'intérpretation. $2^{\mathrm{e}}$ édition corrigée et augmentée. Paris: Didier Érudition/Office des publications officielles des Communautés européennes, 2002.

\title{
Resumo
}

O presente artigo tem como público-alvo o leitor brasileiro e pretende apresentar uma visão panorâmica da interpretação judicial como ocorre nos Estados Unidos, a partir do ponto de vista pessoal de um intérprete atuante no sistema. Pretende, também, discutir algumas das interfaces entre essa modalidade de interpretação e a interpretação de conferências, concluindo por sugerir que um mesmo intérprete pode atuar nas duas situações sem grandes dificuldades.

Palavras-chave: Interpretação judicial; interpretação de conferências; interfaces entre as modalidades; múltiplas atuações do intérprete.

\begin{abstract}
This article is written with the Brazilian reader in mind and aims at showing an overview of court interpreting in the United States, from the viewpoint of an interpreter working regularly in the system. It also aims at discussing some interfaces between court and conference interpreting, leading to a conclusion that a professional interpreter can shift from conference to court and back without any major difficulties.

Keywords: Court interpreting; conference interpreting; interfaces between modalities; interpreters performing in different settings.
\end{abstract}

